\title{
Helicobacter pylori Eradication, a Gordian Knot for Idiopathic Thrombocytopenic Purpura?
}

\author{
Tae Ho Kim and Dae Young Cheung \\ Department of Internal Medicine, The Catholic University of Korea College of Medicine, Seoul, Korea
}

\author{
See "The Effects of Helicobacter pylori Eradication Therapy for Chronic Idiopathic Thrombocytopenic Purpura" by Jae Jin \\ Hwang, et al. on page 356-361, Vol. 10. No. 3, 2016
}

Guidelines for the Diagnosis and Treatment of Helicobacter pylori Infection in Korea was revised in 2013 and idiopathic thrombocytopenic purpura (ITP) was enlisted as a target for $H$. pylori eradication therapy with high level of evidence and strong recommendation grade. ${ }^{1}$ Clinical studies have steadily reported the rise of platelet count after $H$. pylori eradication roughly in a half of the patients with ITP. Regarding the pathogenesis of ITP by $H$. pylori, several immunological and molecular biological mechanisms are proposed and accepted highly reasonable. This is reflected in recently revised Korean guidelines as consistently as other guidelines from other countries including Japan, Europe, and America. ${ }^{2-4}$ However, the national health insurance system does not yet recognize ITP as a subject of insurance benefits for $H$. pylori eradication in Korea. This might be due to insufficiency of Korean data about the effect and possible risk of $H$. pylori eradication on ITP.

The article "The effects of $H$. pylori eradication therapy for chronic idiopathic thrombocytopenic purpura" by Hwang et $a l^{5}$ is a retrospective study performed in Seongnam, Korea. To our best knowledge, this is fourth report about effect of $H$. pylori eradication on ITP in Korea. A total of 102 ITP patients were reviewed. It is the second largest of the world's reports. ${ }^{6}$ The prevalence of $H$. pylori infection was $41.1 \%$ (42/102). It seems compatible with the prevalence of general population in Korea. These results are also similar to those of studies from other countries. Therefore, with studies up to today, the degree of contribution of $H$. pylori to the development of ITP is not estimated from the prevalence of $H$. pylori infection in ITP. Standard triple regimen was given for 7 days and the successful eradication was achieved in 92.9\% (39/42). All patients with successful eradication achieved significant increase in platelet count. Mean platelet counts of baseline and at 6 months after eradication were $43.2 \pm 29.1$ to $155.3 \pm 68.7 \times 10^{3} / \mu \mathrm{L}$ for $H$. pyloripositive and -eradicated group. That change was significantly higher ( $\mathrm{p}=0.041$ ) than those of the $H$. pylori-positive and -noneradicated group and $H$. pylori-negative group $(42.5 \pm 28.1$ to $79.8 \pm 59.7 \times 10^{3} / \mu \mathrm{L}$ and $43.1 \pm 28.9$ to $81.2 \pm 62.2 \times 10^{3} / \mu \mathrm{L}$ ).

The result of this study is consistent with three previous Korean studies. Two retrospective single centered studies were reported in 2008 and 2010. ${ }^{7,8}$ The prevalence of $H$. pylori were $61.7 \%$ and 92\%. Eradication was successful in all patients. Overall response rate ranges from $41.7 \%$ to 68\%. In 2015, a multicenter, open label, prospective phase II study was conducted by hematology researchers. ${ }^{9}$ A total of 26 patients with ITP and $H$. pylori infection were enrolled and the overall response rate reached to $69.2 \%$ during the study period.

ITP is a quite infrequent disease in clinical practice. Health insurance review and assessment service of Korea reported that the number of patients who were coded as ITP, D69.3, was 8,000 in $2015 .^{10}$ Mostly ITP is primary and secondary ITP are related to viral infection, drugs and autoimmune disease. $H$. pylori is one of the causal agents. Due to the rarity of ITP and the academic interest discrepancy between the gastroenterology and hematology, there has been no large scale randomized controlled trials about the effect of $H$. pylori eradication on ITP. Most of ITP patients are treated by hematologist and the conventional treatment for ITP involves the use of immunosuppressive agents, such as corticosteroids, intravenous immunoglobulin, anti-D immunoglobulin, rituximab, thrombopoietin agonists and salvage splenectomy. All of the treatments are expensive

Correspondence to: Dae Young Cheung

Department of Internal Medicine, Yeouido St. Mary’s Hospital, The Catholic University of Korea College of Medicine, 222 Banpo-daero, Seocho-gu, Seoul 06591, Korea

Tel: +82-2-3779-1519, Fax: +82-2-3779-1331, E-mail: adagio@catholic.ac.kr pISSN 1976-2283 eISSN 2005-1212 http://dx.doi.org/10.5009/gnl16095

(a) This is an Open Access article distributed under the terms of the Creative Commons Attribution Non-Commercial License (http://creativecommons.org/licenses/by-nc/4.0) which permits unrestricted non-commercial use, distribution, and reproduction in any medium, provided the original work is properly cited. 
and have a significant risk and adverse effects. On the contrary, $H$. pylori eradication costs less than $\$ 100$ and most of the possible adverse effects are tolerable. Just a simple regimen consists of antibiotics and proton pump inhibitors can be a Gordian knot for roughly a half of ITP patients with $H$. pylori infection. of course, more precise and detailed investigation should be continued. Geographic variation of $H$. pylori stains and prevalence may affect the characteristics of ITP. The eradication rates reported in studies ranges over 90\% to $100 \%$. It is definitely higher than usual situation. The high eradication rates of most retrospective study imply recall bias or selection bias. Prospective controlled trials should be carried out. Patient stratification trial according to the severity of ITP should be performed. Though conditions are not perfectly sufficient, the benefit of $H$. pylori eradication on ITP definitely outweighs the cost and possible risk. It is reasonable time to enlist ITP as a benefit criterion for $H$. pylori eradication in our national health insurance system.

\section{CONFLICTS OF INTEREST}

No potential conflict of interest relevant to this article was reported.

\section{REFERENCES}

1. Kim SG, Jung HK, Lee HL, et al. Guidelines for the diagnosis and treatment of Helicobacter pylori infection in Korea, 2013 revised edition. Korean J Gastroenterol 2013;62:3-26.
2. Malfertheiner P, Megraud F, O'Morain CA, et al. Management of Helicobacter pylori infection: the Maastricht IV/ Florence Consensus Report. Gut 2012;61:646-664.

3. Asaka M, Kato M, Takahashi S, et al. Guidelines for the management of Helicobacter pylori infection in Japan: 2009 revised edition. Helicobacter 2010;15:1-20.

4. Neunert C, Lim W, Crowther M, et al. The American Society of Hematology 2011 evidence-based practice guideline for immune thrombocytopenia. Blood 2011;117:4190-4207.

5. Hwang JJ, Lee DH, Yoon H, Shin CM, Park YS, Kim N. The effects of Helicobacter pylori eradication therapy for chronic idiopathic thrombocytopenic purpura. Gut Liver 2016;10:356-361.

6. Frydman GH, Davis N, Beck PL, Fox JG. Helicobacter pylori eradication in patients with immune thrombocytopenic purpura: a review and the role of biogeography. Helicobacter 2015;20:239-251.

7. Song MK, Chung JS, Shin HJ, Choi YJ, Cho GJ. Outcome of immunosuppressive therapy with Helicobacter pylori eradication therapy in patients with chronic idiopathic thrombocytopenic purpura. J Korean Med Sci 2008;23:445-451.

8. Tag HS, Lee HS, Jung SH, et al. Effects of Helicobacter pylori eradication in patients with immune thrombocytopenic purpura. Korean J Hematol 2010;45:127-132.

9. Kim H, Lee WS, Lee KH, et al. Efficacy of Helicobacter pylori eradication for the 1st line treatment of immune thrombocytopenia patients with moderate thrombocytopenia. Ann Hematol 2015;94:739-746

10. Healthcare Bigdata Hub [Internet]. Wonju: Health Insurance Review \& Assessment Service; c2015 [cited 2016 Mar 25]. Available from: http://opendata.hira.or.kr/home.do. 